\title{
Analisis Pengaruh Perubahan Penggunaan Lahan terhadap Debit Sungai (Studi Kasus : Sub DAS Cikeas)
}

\author{
(Analysis of Land Use Change Influence to River Discharge \\ (Study Case: Cikeas Sub-Basin ))
}

I Gede Aditya Dharma ${ }^{1}$, Roh Santoso Budi Waspodo ${ }^{1}$, dan Nora Herdiana Pandjaitan ${ }^{\text {* }}$

${ }^{1}$ Departemen Teknik Sipil dan Lingkungan, Fakultas Teknologi Pertanian, Institut Pertanian Bogor. J1. Raya Dramaga, Kampus IPB Dramaga, PO BOX 220, Bogor, Jawa Barat, Indonesia

* Penulis korespondensi: norahp@apps.ipb.ac.id

\section{ABSTRACT}

Land use change have an impact on infiltration capacity. There is often an annual flood on Kadumanggu District. When the rainfall is high so the river will be overflow. The outlet of Cikeas subbasin was located on Kadumanggu District. This research aimed to determine the maximum discharge of the Cikeas River and analyze the relation between land use change and discharge of Cikeas River. The research was conducted by delineating the water catchment area, analyzing rainfall, making a land use map and modeling with HEC-HMS. Based on the modeling results, the maximum discharge of the Cikeas River in 2000 was $74.3 \mathrm{~m}^{3} / \mathrm{s}$, in 2009 was $84.9 \mathrm{~m}^{3} / \mathrm{s}$, and in 2018 was $91.7 \mathrm{~m}^{3} / \mathrm{s}$. The catchment area with an extensive use as residential had a higher river discharge compared to the area with a large green area. It meaned that, land use changes greatly affected the river discharge.

Keywords: HEC-HMS, Rainfall, Residential, Catchment Area

\section{PENDAHULUAN}

Fungsi dari daerah aliran sungai (DAS) adalah sebagai pemasok air dengan kuantitas dan kualitas yang baik terutama bagi orang di daerah hilir (Wahid 2009). Manfaat sungai antara lain sebagai sumber air untuk kebutuhan irigasi, penyediaan air minum, kebutuhan industri, pariwisata, pengembangan perikanan, dan juga sebagai saluran pembuangan untuk menampung air selokan dan air buangan dari areal pertanian (Kamase 2017). Persepsi umum yang berkembang pada saat ini, konversi hutan menjadi lahan pertanian mengakibatkan penurunan fungsi hutan dalam mengatur tata air, mencegah banjir, longsor dan erosi pada DAS tersebut (Farida \& Noordwijk 2004).
Perubahan pola penggunaan lahan memberi dampak pada pengurangan kapasitas resapan, terutama dilihat dari proporsi perubahan luasan hutan, sehingga akan meningkatkan laju limpasan permukaan yang dapat berpotensi menghasilkan banjir di kawasan hilir (Permatasari et al. 2017). Perubahan pola penggunaan lahan berpengaruh pada penurunan ketersediaan air akibat meningkatnya bencana banjir yang semakin ekstrim (Supit \& Mamoto 2016).

Peningkatan debit sungai dapat menimbulkan luapan air sungai yang menyebabkan banjir pada wilaya sekitar DAS (Ayivor \& Gordon 2012). Berdasarkan hal tersebut, dibutuhkan daya dukung sistem hidrologi DAS yang baik agar dapat mencegah banjir yang terjadi pada sekitar wilayah DAS (Berutu et al. 2015). Penilaian kepekaan 
dan daya dukung sistem hidrologi DAS akibat perubahan penggunaan lahan dapat dilakukan dengan simulasi hidrologi wilayah (Wibowo 2005).

Tujuan penelitian ini adalah untuk menganalisis besarnya debit puncak Sungai Cikeas saat curah hujan tinggi, mempelajari hubungan perubahan penggunaan lahan terhadap debit sungai di sub DAS Cikeas, dan menganalisis penyebab terjadinya luapan Sungai Cikeas.

\section{METODOLOGI}

Penelitian dilaksanakan di Kabupaten Bogor dari bulan Mei hingga Juli 2020. Lokasi penelitian merupakan sub DAS Cikeas yang bertempat di Kecamatan Babakan Madang, Identifikasi penyebab banjir akan dilaksanakan di daerah sub DAS Cikeas. Alat yang digunakan yaitu smartphone, alat tulis, kalkulator, serta laptop yang dilengkapi dengan ArcGIS, HEC-HMS 4.3, program Microsoft Word, Microsoft Excel, dan Google Earth. Bahan yang digunakan pada penelitian kali ini adalah data curah hujan Kabupaten Bogor (periode 2010-2019), peta jenis tanah Kabupaten Bogor, peta penggunaan lahan DAS Cikeas dan data SRTM. Tahapan penelitian disajikan dalam bentuk diagram alir pada Gambar 1 .

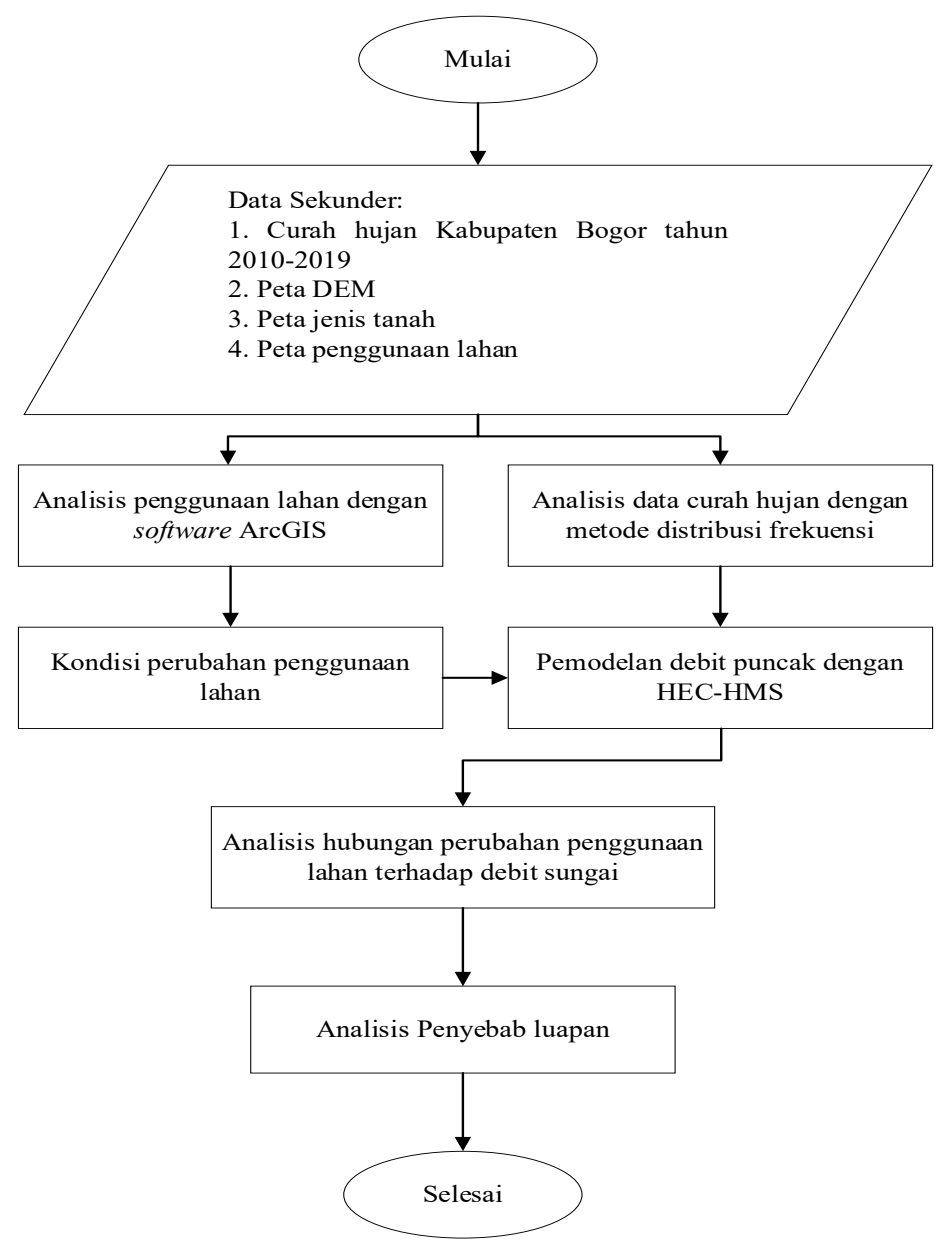

Gambar 1 Diagram alir tahapan penelitian 
Tahapan penelitian meliputi studi pustaka, pengumpulan data dan informasi, serta pengolahan dan analisis data.

\section{Analisis Curah Hujan}

Curah hujan (mm) merupakan ketinggian air hujan yang jatuh pada tempat yang datar dengan asumsi tidak menguap, tidak meresap dan tidak mengalir (Mulyono 2014). Analisis frekuensi dan probabilitas hujan dilakukan dengan metode distribusi Normal, Log Normal, Log Pearson III, dan Gumbel. Pengujian kecocokan distribusi dilakukan dengan metode Chi Kuadrat. Curah hujan yang digunakan dalam menentukan persamaan yang akan digunakan adalah data curah hujan 10 tahun terakhir.

Fungsi probabilitas Normal dapat dianalisis dengan persamaan (1).

$X_{T}=\bar{x}+K_{T} \times S$

Fungsi probabilitas Log Normal dapat dianalisis dengan persamaan (2).

$\log X_{T}=\log \bar{x}+K_{T} \cdot \log \bar{x}$

Persadaam probabilitas Gumbel dianalisa dengan persamaan (3) dan (4).

$X_{T r}=b+\frac{1}{a} Y_{T}$

$a=\frac{s n}{s}$ dan $b=\bar{x} \frac{Y n S}{s n}$

Persamaan distribusi Log Pearson III disajikan pada persamaan (5).

$\log X_{T}=\log \bar{x}+K \times S$

Keterangan :

$\begin{aligned} \mathrm{X}_{\mathrm{T}}= & \text { perkiraan nilai yang } \\ & \text { diharapkan terjadi dengan } \\ & \text { periode ulang T-tahunan } \\ \overline{\mathrm{X}} & =\text { nilai rata-rata } \\ \mathrm{S} & =\text { standar deviasi } \\ \mathrm{K}_{\mathrm{T}}= & \text { faktor frekuensi } \\ \log \mathrm{X}_{\mathrm{T}}= & \text { perkiraan nilai yang }\end{aligned}$

$$
\begin{array}{ll} 
& \begin{array}{l}
\text { diharapkan terjadi } \\
\text { dengan periode ulang } \mathrm{T}- \\
\\
\text { tahunan }(\mathrm{Log})
\end{array} \\
\overline{\mathrm{x}} \quad & \text { nilai rata-rata } \\
\mathrm{X}_{\mathrm{Tr}} \quad= & \text { perkiraan nilai yang } \\
& \text { diharapkan terjadi dengan } \\
& \text { periode ulang T tahunan } \\
\mathrm{YT} \quad= & \text { reduced variate } \\
\mathrm{Sn} \quad= & \text { reduced standard deviation } \\
\mathrm{Yn} \quad= & \text { reduced mean }
\end{array}
$$

\section{HEC-HMS 4.3}

Model hidrologi dengan program HEC-HMS dirancang untuk mensimulasikan proses hujan-limpasan dari sistem aliran. Program ini dirancang agar dapat diaplikasikan dalam luasan tertentu untuk merepresentasikan proses hidrologi DAS (Sardoii et al. 2012). Perhitungan intensitas hujan harian menjadi hujan jam-jaman dapat dilakukan dengan menggunakan persamaan Mononobe pada persamaan (6) (Asdak 2014). Dengan demikian akan terbentuk hyetograph rencana, rumus dapat dilihat pada persamaan (7) dan (8) (Triatmodjo 2016). Perhitungan loss model dalam metode SCS curve number menggunakan nilai IA dan curve number dengan persamaan (9) (Risyanto 2007).

$$
\begin{aligned}
& I t=\left(\mathrm{R}_{24} / 24\right) \times\left(\frac{24}{t}\right)^{\wedge} \frac{2}{3} \\
& T d=n x \Delta t \ldots \ldots \ldots \ldots \ldots \ldots \\
& I_{t} T_{d}=I x T_{d} \ldots \ldots \ldots \ldots \ldots
\end{aligned}
$$

Keterangan :

$$
\begin{aligned}
\text { It } & =\text { intensitas curah hujan } \\
& \quad(\mathrm{mm} / \text { jam }) \\
\mathrm{R} 24= & \text { curah hujan maksimum selama } \\
& 24 \text { jam (mm) } \\
\mathrm{T} & =\text { lama hujan (jam) } \\
\mathrm{n} & =\text { data } \\
\Delta \mathrm{t} \quad= & \text { pertambahan hujan dalam } \\
& \quad \text { interval waktu } \\
\mathrm{Td} \quad= & \text { waktu (jam) }
\end{aligned}
$$




\section{HASIL DAN PEMBAHASAN}

\section{Keadaan Umum Lokasi Penelitian}

DAS Cikeas merupakan bagian dari DAS Bekasi Hulu dengan batas hilir dari DAS Bekasi Hulu terdapat di Bendung Bekasi. Luas DAS Cikeas secara keseluruhan sebesar 11.353 ha dengan variasi kemiringan lereng antara 0-15\%. Sungai Cikeas memiliki panjang $49.924 \mathrm{~m}$ dengan lebar sungai 10-25 m. Kondisi topografi pada DAS Cikeas adalah datar hingga bergelombang dengan elevasi 27-460 meter di atas permukaan laut (Mdpl). Wilayah administrasi DAS Cikeas meliputi Kabupaten Bogor dan Bekasi.

Delineasi daerah tangkapan air (DTA) pada sub DAS Cikeas dilakukan dengan menggunakan peta digital elevation model (DEM) yang didapatkan dari DEMNAS. Titik outlet pada peta terdapat di Kadumanggu yang merupakan titik yang sering tergenang oleh luapan sungai. Pembuatan DTA dengan pengolahan data DEM dilakukan dengan program arcGIS. Berdasarkan hasil DTA yang telah dibuat, panjang sungai Cikeas pada data tersebut sebesar $6,8 \mathrm{~km}$ dan luas DTA sebesar 556,66 ha.

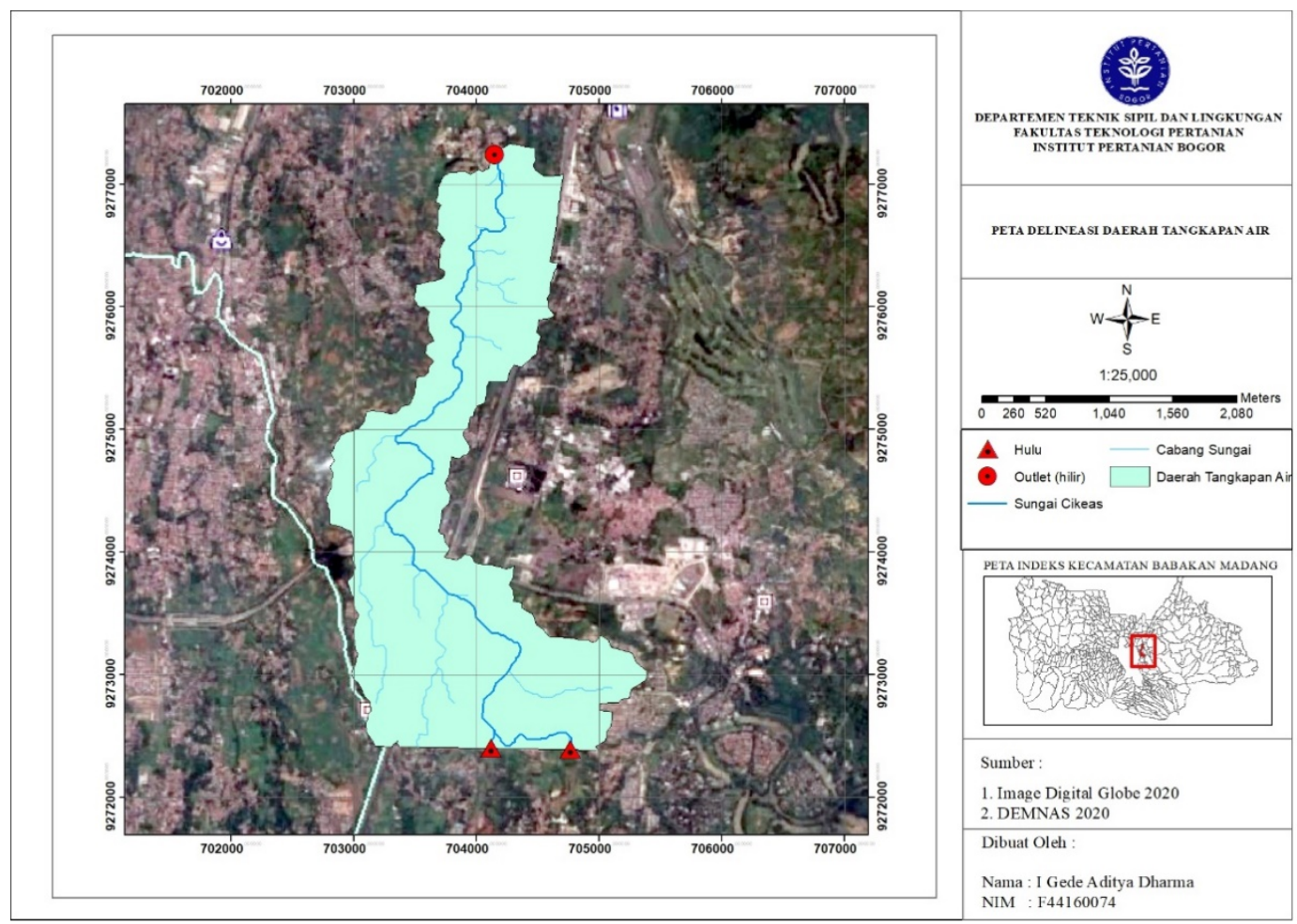

Gambar 2 Peta Daerah Tangkapan Air

Jenis Tanah

Peta jenis tanah yang dipakai adalah peta jenis tanah Kabupaten Bogor. Berdasarkan peta tersebut, jenis tanah yang ada pada daerah penelitian adalah tanah latosol. Tanah latosol merupakan tanah bertekstur lempung berpasir. Tanah dengan tekstur lempung memiliki tingkat infiltrasi lebih rendah dibandingkan dengan tanah dengan tekstur pasir. Rendahnya tingkat infiltrasi menyebabkan besarnya nilai limpasan permukaan pada daerah dengan tanah bertekstur liat. Klasifikasi tanah berdasarkan kelas tekstur tanah meninjau pada USDA (1986) yang dapat dilihat pada Tabel 1. 
Tabel 1 Klasifikasi Grup Hidrologi Tanah Berdasarkan Tekstur

\begin{tabular}{cl}
\hline HSG & \\
\hline A & Pasir, pasir bertanah liat, atau pasir berlempung \\
B & Lempung atau Lempung berpasir \\
C & Lempung berdebu dan lempung liat berdebu \\
D & Tanah liat, liat berlempung, liat berpasir \\
\hline
\end{tabular}

Jenis tanah latosol termasuk ke dalam ordo tanah ultisol. Tanah ultisol merupakan tanah muda yang umumnya belum berkembang lanjut sehingga kebanyakan tanah ini cukup subur. Berdasarkan tekstur tanah dan sifat hidrologinya, tanah yang ada di sub DAS Cikeas termasuk ke dalam HSG tipe B. Menurut (Kadri 2011), tanah yang ada pada daerah Cikeas terdiri atas tanah paleudults, eutropepts dan tropudelfs. Tanah paleudults dan eutropepts termasuk ke dalam jenis tanah ultisol sehingga masuk ke dalam kelompok hidrologi tanah B.

\section{Penggunaan Lahan}

Peningkatan limpasan dengan curah hujan tetap dapat menibulkan peningkatan debit sungai yang dapat mengakibatkan meluapnya air sungai dan dapat menimbulkan banjir (Ismoyojati et al. 2018). Perubahan penggunaan lahan pada sub-DAS Cikeas dapat dilihat pada Gambar 3, Gambar 4, dan Gambar 5.

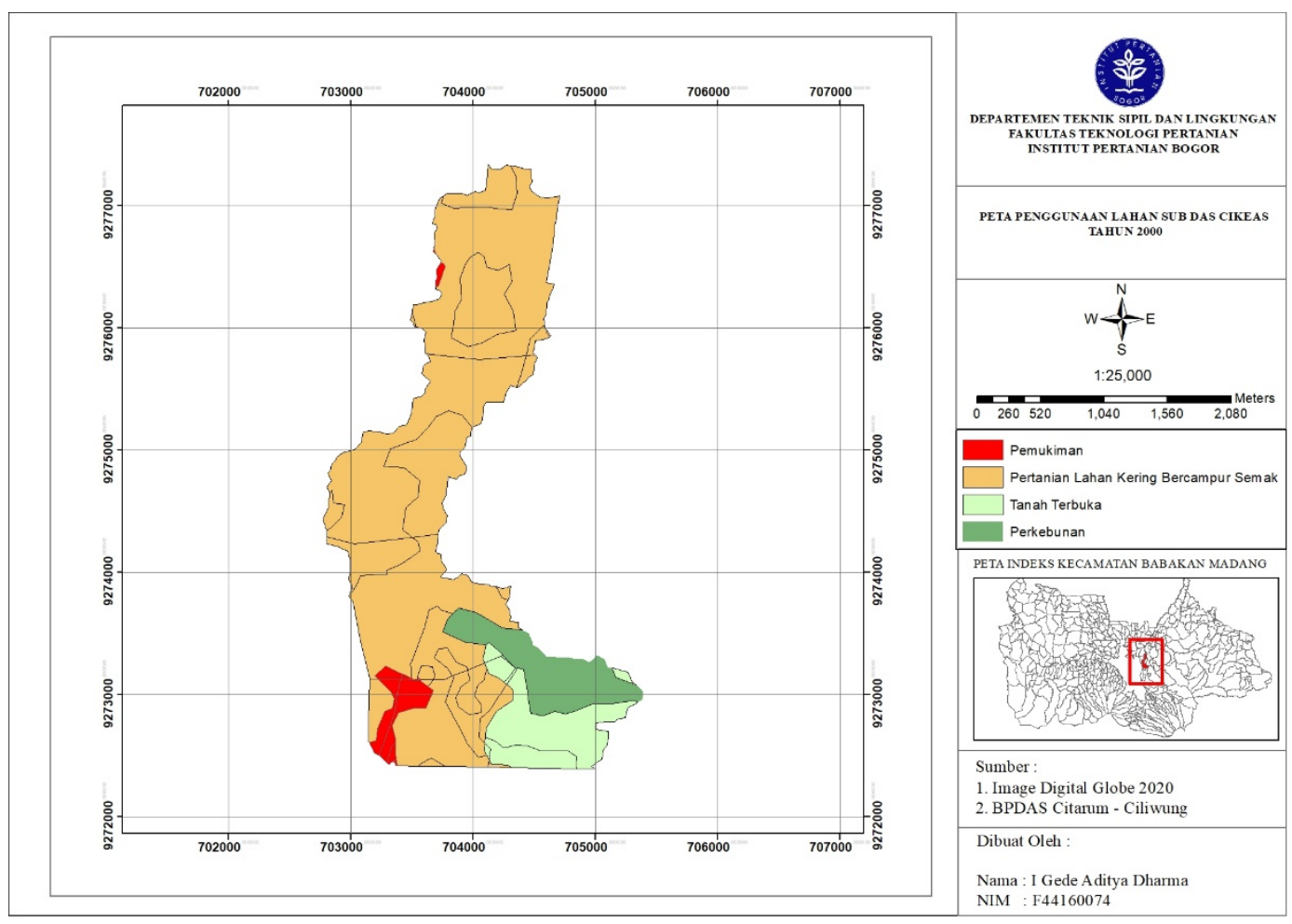

Gambar 3 Peta Penggunaan Lahan Tahun 2000 


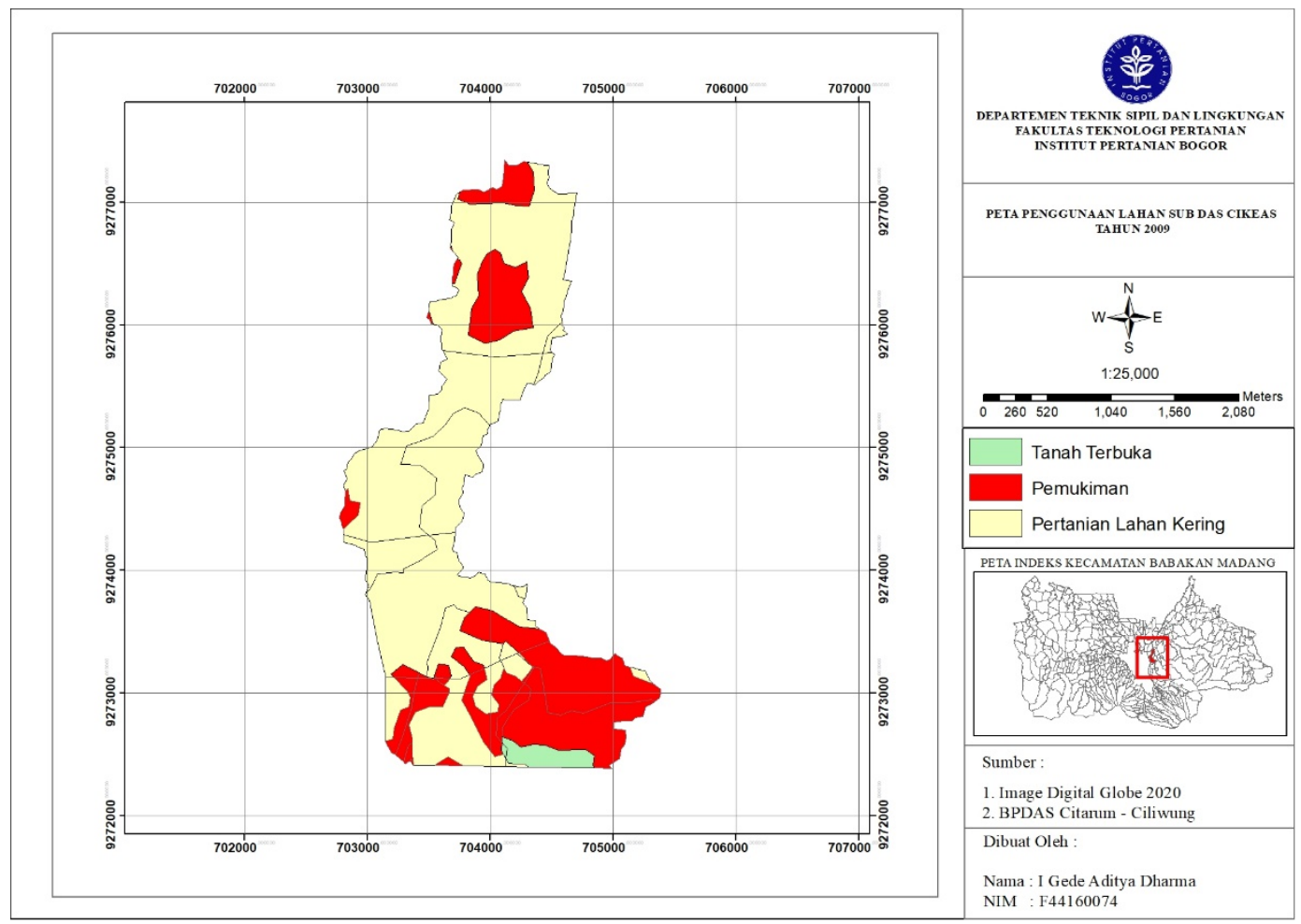

Gambar 4 Peta Penggunaan Lahan Tahun 2009
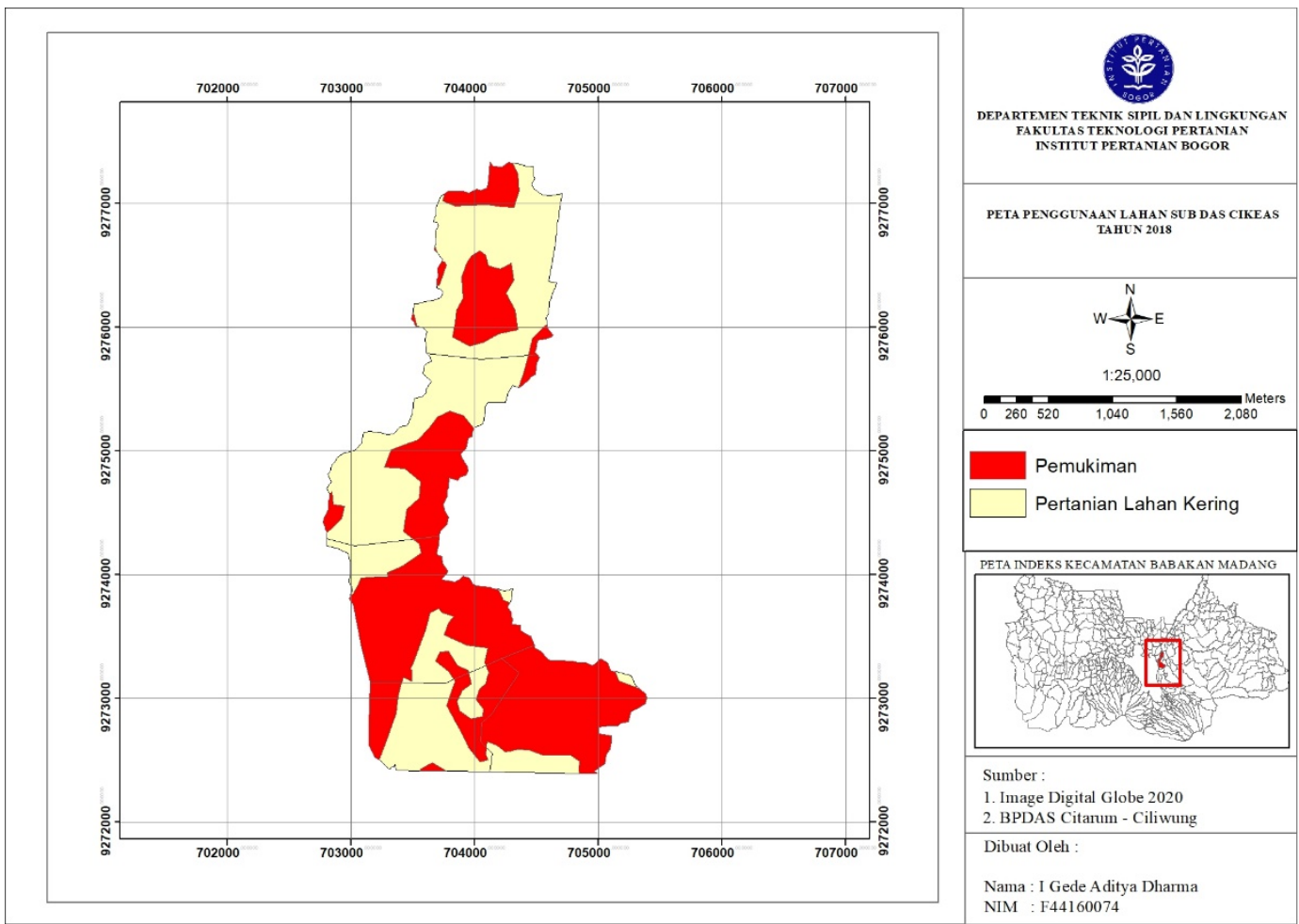

Gambar 5 Peta Penggunaan Lahan Tahun 2018

Berdasarkan data pada gambar 3, luas dari penggunaan lahan dapat dilihat pada Tabel 2. Total luas dari daerah tangkapan air pada sub-DAS Cikeas adalah 556.66 ha. Penggunaan lahan pada tahun 2000 didominasi oleh pertanian lahan kering bercampur semak yaitu sebesar $77.56 \%$ dari total luas 
lahan. Tahun 2009 terjadi perubahan penggunaan lahan dari pertanian lahan kering bercampur semak menjadi pertanian lahan kering, dengan terdapat peningkatan pada lahan pemukiman.
Penggunaan lahan untuk pemukiman meningkat dari $3.01 \%$ total luas lahan pada tahun 2000 menjadi $30.91 \%$ pada tahun 2009 dan menjadi $50.48 \%$ total luas lahan pada tahun 2018 .

Tabel 2 Penggunaan Lahan Lokasi Penelitian

\begin{tabular}{|c|c|c|c|c|}
\hline \multirow{2}{*}{ Tahun } & \multirow{2}{*}{ Penggunaan Lahan } & \multicolumn{2}{|c|}{ Luas } & \multirow{2}{*}{ Total (ha) } \\
\hline & & (ha) & $(\%)$ & \\
\hline \multirow[t]{4}{*}{2000} & Tanah Terbuka & 57.18 & 10.27 & \multirow{4}{*}{556.66} \\
\hline & Perkebunan & 51.00 & 9.16 & \\
\hline & Pertanian Lahan Kering Bercampur Semak & 431.74 & 77.56 & \\
\hline & Pemukiman & 16.74 & 3.01 & \\
\hline \multirow[t]{3}{*}{2009} & Tanah Terbuka & 11.76 & 2.11 & \multirow{3}{*}{556.66} \\
\hline & Pertanian Lahan Kering & 372.82 & 66.97 & \\
\hline & Pemukiman & 172.08 & 30.91 & \\
\hline \multirow[t]{2}{*}{2018} & Pertanian Lahan Kering & 275.65 & 49.52 & \multirow{2}{*}{556.66} \\
\hline & Pemukiman & 281.01 & 50.48 & \\
\hline
\end{tabular}

\section{Analisis Curah Hujan}

Data curah hujan pada penelitian ini menggunakan data curah hujan Stasiun Badan Meteorologi, Klimatologi, dan Geofisika (BMKG) Dramaga, Bogor. Menurut Asdak
(2014), perhitungan analisis hujan seperti kedalaman dan intensitas curah hujan menggunakan data minimal 10 tahun. Data yang digunakan adalah data dari tahun 2010 hingga tahun 2019. Data curah hujan harian maksimum dapat dilihat pada Tabel 3 .

Tabel 3 Curah Hujan Harian Maksimum per Tahun (mm)

\begin{tabular}{cccc}
\hline Tahun & CH maks $(\mathrm{mm})$ & Tahun & CH maks $(\mathrm{mm})$ \\
\hline 2010 & 144.5 & 2015 & 155.8 \\
2011 & 97.6 & 2016 & 108.6 \\
2012 & 116.0 & 2017 & 117.6 \\
2013 & 97.4 & 2018 & 134.5 \\
2014 & 169.1 & 2019 & 141.0 \\
\hline
\end{tabular}

Curah hujan harian tertinggi terdapat di tahun 2014 sebesar $169.1 \mathrm{~mm}$ dan curah hujan terendah terdapat di tahun 2013 sebesar $97.4 \mathrm{~mm}$. Perhitungan nilai curah hujan dilakukan dengan menggunakan metode distribusi probabilitas. Hasil analisis frekuensi curah hujan rencana dengan periode ulang 2, 5, 10, 50, 100 tahun dapat dilihat pada Tabel 4 . 
JSIL | Dharma dkk. : Analisis Pengaruh Perubahan Lahan terhadap Debit Sungai

Tabel 4 Hasil Analisis Frekuensi Curah Hujan Rencana

\begin{tabular}{ccrrr}
\hline & \multicolumn{4}{c}{ Curah Hujan Rencana (mm) } \\
\cline { 2 - 4 } Periode Ulang (Tahun) & Normal & Log Normal & Log Pearson III & Gumbel \\
\hline 2 & 128.210 & 126.102 & 126.058 & 124.880 \\
5 & 148.851 & 148.198 & 148.067 & 154.209 \\
10 & 159.662 & 161.276 & 161.663 & 173.627 \\
50 & 178.583 & 187.002 & 189.186 & 216.364 \\
100 & 185.463 & 197.342 & 200.258 & 234.431 \\
\hline
\end{tabular}

Hasil perhitungan analisis curah hujan menunjukkan perbedaan nilai dari setiap distribusi yang digunakan. Peninjauan syarat batas parameter statistik dari tiap distribusi maka diperlukan parameter pembading bedasarkan data pengamatan. Parameter pembanding akan ditentukan berdasarkan nilai yang memenuhi persyaratan koefisien kemencengan (Cs) dan koefisien kurtosis (Ck). Nilai Cs dan $\mathrm{Ck}$ dari masing-masing distribusi berbeda. Hasil perbandingan dapat dilihat pada Tabel 5.

Tabel 5 Hasil Perbandingan Parameter Distribusi

\begin{tabular}{cccccc}
\hline \multirow{2}{*}{ Distribusi } & \multicolumn{2}{c}{ Perhitungan } & \multicolumn{2}{c}{ Syarat } & \multirow{2}{*}{ Keterangan } \\
\cline { 2 - 4 } & $\mathrm{Cs}$ & $\mathrm{Ck}$ & $\mathrm{Cs}$ & $\mathrm{Ck}$ & \\
\hline Normal & 0.258 & -1.085 & $=0$ & $=3$ & Tidak Memenuhi \\
Gumbel & 0.258 & -1.085 & $=1.14$ & $=5.4$ & Tidak Memenuhi \\
Log Normal & $2.614 \mathrm{E}-45$ & 1.411 & $=0.208$ & $=3.077$ & Tidak Memenuhi \\
Log Pearson III & $2.614 \mathrm{E}-45$ & 1.411 & Selain nilai diatas & Memenuhi \\
\hline
\end{tabular}

Berdasarkan Tabel 5 hasil perbandingan parameter pada distribusi Normal, Gumbel, dan Log Normal tidak memenuhi syarat. Parameter distribusi yang memenuhi syarat adalah distribusi Log Pearson III dengan nilai Cs 2.614E45 dan nilai $\mathrm{Ck} 1.411$, sehingga nilai curah hujan rencana yang akan digunakan pada tahap perhitungan selanjutnya adalah nilai curah hujan rencana Log Pearson III. Untuk menentukan apakah persamaan distribusi yang digunakan telah mewakili distribusi statistik sampel data yang dianalisis maka dilakukan uji Chi Kuadrat. Hasil pengujian Chi Kuadrat dapat dilihat pada Tabel 6. Syarat yang perlu dipenuhi dalam uji Chi Kuadrat adalah nilai X2 $<$ X2cr. Nilai X2cr sebesar 5.991 didapatkan dari tabel Chi Kuadrat. Nilai X2 perhitungan pada Tabel 6 adalah 1. Maka nilai $1<5.991$ memenuhi syarat yang diperlukan dan nilai curah hujan yang digunakan adalah nilai distribusi Log Pearson III.

Tabel 6 Hasil Perhitungan Chi Kuadrat untuk Persamaan Log Pearson III

\begin{tabular}{|c|c|c|c|c|c|}
\hline Sub kelompok & Oi & $\mathrm{Ei}$ & Oi-Ei & $(\mathrm{Oi}-\mathrm{Ei})^{2}$ & $(\mathrm{Oi}-\mathrm{Ei})^{2} / \mathrm{Ei}$ \\
\hline $88.437-106.362$ & 2 & 2 & 0 & 0 & 0 \\
\hline $106.362-124.287$ & 3 & 2 & 1 & 1 & 0.5 \\
\hline $124.287-142.212$ & 2 & 2 & 0 & 0 & 0 \\
\hline $142.212-160.137$ & 2 & 2 & 0 & 0 & 0 \\
\hline $160.137-178.062$ & 1 & 2 & -1 & 1 & 0.5 \\
\hline & & & & $\mathrm{X}^{2}$ & 1 \\
\hline
\end{tabular}

Berdasarkan (KemenPU 2012) untuk luas daerah tangkapan air yang lebih besar dari 500 ha maka nilai curah hujan yang digunakan adalah nilai curah 
hujan dengan periode ulang 10 tahun yaitu sebesar $161.663 \mathrm{~mm}$. hujan rancangan diperlukan dalam menghitung banjir rancangan. Nilai hujan rancangan didistribusikan ke dalam hujan jamjaman atau hyetograph. Pendistribusian hujan harian ke dalam hujan jam-jaman dilakukan dengan model distribusi alternating block method (ABM). Hasil perhitungan ABM disajikan pada Tabel 7.

Tabel 7 Hasil Perhitungan ABM Periode Ulang 10 Tahun

\begin{tabular}{ccccrrrr}
\hline \multirow{2}{*}{ Td (Jam) } & $\Delta$ (jam) & lt (mm/jam) & ltTd $(\mathrm{mm})$ & $\Delta \mathrm{P}(\mathrm{mm})$ & $\mathrm{Pt}(\%)$ & \multicolumn{2}{c}{ Hyetograph } \\
\hline 1 & $0-1$ jam & 56.05 & 56.05 & 56.05 & 55.03 & 6.75 & 10.91 \\
2 & $1-2$ jam & 35.31 & 70.61 & 14.57 & 14.30 & 10.03 & 16.22 \\
3 & $2-3$ jam & 26.94 & 80.83 & 10.22 & 10.03 & 55.03 & 88.97 \\
4 & 3-4 jam & 22.24 & 88.97 & 8.14 & 7.99 & 14.30 & 23.12 \\
5 & 4-5 jam & 19.17 & 95.84 & 6.87 & 6.75 & 7.99 & 12.91 \\
6 & 5-6 jam & 16.97 & 101.84 & 6.00 & 5.90 & 5.90 & 9.53 \\
\hline \multicolumn{2}{c}{ Jumlah } \\
\hline
\end{tabular}

Menurut (Triatmodjo 2016), curah hujan dengan nilai lebih besar dari 100 mm maka menggunakan waktu hujan jam-jaman 6 jam. Hasil perhitungan ABM berupa nilai hyetograph yang nantinya akan digunakan sebagai pemodelan. Berdasarkan tabel 5, persen intensitas terbesar yaitu $55.03 \%$ dengan intensitas hujan $88.97 \mathrm{~mm}$ dan terkecil sebesar $5.90 \%$ dengan intensitas hujan $9.53 \mathrm{~mm}$.

\section{Analisis HEC-HMS}

Analisis HEC-HMS dilakukan untuk melihat hubungan perubahan penggunaan lahan terhadap debit sungai. Besarnya nilai $\mathrm{CN}$ dapat dilihat pada Tabel 8. Jenis tanah pada lokasi penelitian termasuk ke dalam HSG tipe $\mathrm{B}$, sehingga nilai $\mathrm{CN}$ untuk masingmasing penggunaan lahan adalah 85 untuk pemukiman, 73 untuk pertanian lahan kering bercampur semak, 76 untuk pertanian lahan kering, 81 untuk perkebunan, dan 79 untuk tanah terbuka.

Tabel 8 Nilai Curve Number untuk Tiap Penggunaan Lahan

\begin{tabular}{|c|c|c|c|c|c|}
\hline \multirow{2}{*}{ Penggunaan lahan } & \multicolumn{4}{|c|}{ HSG } & \multirow{2}{*}{ Tipe Penggunaan Lahan } \\
\hline & $\mathrm{A}$ & $\mathrm{B}$ & $\mathrm{C}$ & $\mathrm{D}$ & \\
\hline Pemukiman & 77 & 85 & 90 & 92 & $\begin{array}{l}\text { residentian districts, } 1 / 8 \text { acre or } \\
\text { less }\end{array}$ \\
\hline $\begin{array}{l}\text { Pertanian Lahan Kering } \\
\text { Bercampur Semak }\end{array}$ & 57 & 73 & 82 & 86 & $\begin{array}{l}\text { Woods-grass combination, poor } \\
\text { condition }\end{array}$ \\
\hline Pertanian Lahan Kering & 65 & 76 & 84 & 88 & $\begin{array}{l}\text { Small Grain, Straight Row (SR), } \\
\text { poor condition }\end{array}$ \\
\hline Perkebunan & 72 & 81 & 88 & 91 & $\begin{array}{l}\text { Row Crops, Straight Row (SR), } \\
\text { poor condition }\end{array}$ \\
\hline Tanah Terbuka & 68 & 79 & 86 & 89 & open spaces, poor condition \\
\hline
\end{tabular}

Pemodelan dilakukan dengan melakukan pembagian wilayah sub DAS menjadi 5 bagian. Pembagian wilayah dilakukan berdasarkan topografi yang 
ada di wilayah sub DAS dan berakhir di titik outlet. Masing-masing bagian memiliki subbasin berdasarkan penggunaan lahan yang ada pada bagian tersebut. Data luas penggunaan lahan, nilai $\mathrm{CN}$, dan initian abstraction (IA) dimasukkan ke dalam model subbasin. Pemodelan dilanjutkan dengan menambah komponen data time series data yang berisikan data hyetograph yang telah dihitung. Selanjutnya dilakukan perhitungan nilai debit yang dihasilkan dari pemodelan. Hasil debit pada pemodelan dapat dilihat pada Tabel 9.

Tabel 9 Debit Puncak Pemodelan HEC-HMS

\begin{tabular}{cccccc}
\hline \multicolumn{2}{l}{2000} & \multicolumn{2}{c}{2009} \\
\hline Jam Ke- & Debit $\left(\mathrm{m}^{3} /\right.$ detik $)$ & Jam ke- & Debit $\left(\mathrm{m}^{3} /\right.$ detik $)$ & Jam ke- & Debit $\left(\mathrm{m}^{3} /\right.$ detik $)$ \\
\hline 1 & 0 & 1 & 0 & 1 & 0.1 \\
2 & 1.7 & 2 & 3.6 & 2 & 4.8 \\
3 & 74.3 & 3 & 84.9 & 3 & 91.7 \\
4 & 32.8 & 4 & 35.1 & 4 & 34.6 \\
5 & 17.7 & 5 & 18.6 & 5 & 18.7 \\
6 & 12.9 & 6 & 13.5 & 6 & 13.6 \\
\hline
\end{tabular}

Berdasarkan hasil pemodelan dengan HEC-HMS, terdapat perbedaan debit puncak pada tahun 2000, 2009, dan 2018. Debit puncak yang dihasilkan pada tahun 2000 adalah sebesar $74.3 \mathrm{~m}^{3} /$ detik, tahun 2009 sebesar $84.9 \mathrm{~m}^{3} /$ detik, dan tahun 2018 sebesar $91.7 \mathrm{~m}^{3} /$ detik. Berdasarkan data tersebut, terjadi kenaikan debit puncak pada setiap tahunnya. Kenaikan debit tersebut diakibatkan oleh perubahan penggunaan lahan menjadi pemukiman. Penggunaan lahan pada tahun 2000 dengan luas lahan pemukiman yang masih kecil menghasilkan debit puncak yang lebih rendah dibandingkan dengan penggunaan lahan pada tahun 2018, karena sebagian besar sub-DAS pada tahun 2018 sudah tertutupi dengan pemukiman. Hal tersebut menandakan bahwa perubahan penggunaan lahan dapat mempengaruhi besar debit yang dihasilkan di daerah sub-DAS Cikeas.

\section{Penyebab Luapan dan Penanggulangannya}

Berdasarkan data hasil analisis HEC-HMS yang telah dilakukan, terjadi kenaikan debit puncak sungai akibat perubahan penggunaan lahan. Perubahan lahan menjadi pemukiman mengurangi kemampuan tanah untuk menyerap air, sehingga limpasan yang terjadi akibat hujan terjadi dengan lebih cepat dan mengalir langsung menuju sungai. Kondisi bantaran sungai yang dimanfaatkan sebagai pemukiman dan pertanian juga dapat menimbulkan sedimen seperti sampah yang dapat mengurangi volume tampung sungai. Peningkatan debit tanpa disertai dengan peningkatan kapasitas sungai menyebabkan air sungai meluap dan membanjiri area sekitar DAS.

Solusi yang dapat diberikan untuk menanggulangi luapan Sungai Cikeas adalah dengan melakukan normalisasi sungai. Normalisasi sungai dilakukan untuk memperluas profil sungai untuk dapat menampung debit air yang terjadi saat curah hujan tinggi. Berdasarkan 
pada PP Nomor 38 tahun 2011 pasal 10 tentang sempadan sungai, Sungai Cikeas termasuk ke dalam sungai kecil dengan luas DAS kurang dari atau sama dengan $500 \mathrm{~km}^{2}$. Sehingga garis sempadan sungai paling sedikit $50 \mathrm{~m}$ dari tepi kiri dan kanan palung sungai.

Normalisasi atau naturalisasi sungai yang dilakukan didasari atas kondisi penggunaan lahan yang ada pada setiap wilayah bagian pada sub DAS Cikeas. Wilayah sub DAS Cikeas bagian 1,2, dan 3 dilakukan normalisasi dengan pengerukan sedimen pada sungai. Hal ini bertujuan untuk meningkatkan kapasitas sungai. Wilayah sub DAS Cikeas bagian 4 dan 5 dilakukan naturalisasi sungai atas dasar fungsi sub DAS pada bagian hulu yaitu konservasi. Naturalisasi dilakukan dengan melakukan penanaman vegetasi pada sempadan sungai agar dapat mengembalikan kawasan sungai sebagai daerah resapan air. Selain itu, untuk mengurangi limpasan akibat curah hujan tinggi, juga dapat dilakukan dengan pembuatan sumur resapan pada daerah pemukiman.

\section{KESIMPULAN}

Berdasarkan hasil dari penelitian yang telah dilakukan, dapat disimpulkan bahwa:

1. Debit puncak Sungai Cikeas pada tahun 2000 sebesar $74.3 \mathrm{~m} 3 /$ detik, tahun 2009 sebesar $84.9 \mathrm{~m} 3 /$ detik, dan tahun 2018 sebesar 91.7 $\mathrm{m} 3 /$ detik. Debit tertinggi terjadi pada tahun 2018 dengan kondisi penggunaan lahan pemukiman seluas $50.48 \%$ dan pertanian lahan kering seluas $49.52 \%$ dari total DTA.

2. Perubahan penggunaan lahan dari lahan pertanian, perkebunan dan tanah terbuka menjadi pemukiman pada sub DAS Cikeas mempengaruhi debit Sungai Cikeas. Berdasarkan hasil perubahan debit sungai tahun 2000, 2009, dan 2018 terlihat bahwa semakin besar perubahan penggunaan lahan menjadi pemukiman maka debit sungai yang dihasilkan menjadi semakin tinggi.

3. Penyebab dari terjadinya luapan Sungai Cikeas adalah meningkatnya debit Sungai Cikeas akibat perubahan penggunaan lahan dan berkurangnya kapasitas sungai akibat sedimen seperti sampah.

\section{DAFTAR PUSTAKA}

Asdak C. 2014. Hidrologi dan Pengelolaan Daerah Aliran Sungai. Yogyakarta: Gajah Mada University Press.

Ayivor JS, Gordon C. 2012. Impact of land use on river systems in Ghana. West African Journal of Applied Ecology. 20 (3): 83-95.

Berutu N, Lumbataruan W, Astuti A, Rohani. 2015. Analisis daya dukung lingkungan daerah aliran Sungai Deli. Jurnal Pengabdian Kepada Masyarakat. 21 (79): 7884.

Farida, Noordwijk MV. 2004. Analisis debit sungai akibat alih guna lahan dan aplikasi model genriver pada DAS Way Besai, Sumberjaya. AGRIVITA. 26 (1): 39-47.

Ismoyojati G, Sujono J, Jayadi R. 2018. Studi pengaruh perubahan tataguna lahan terhadap karakteristik banjir Kota Bima. Jurnal Geofrafi Lingkungan Tropik. 2 (2): 14-27.

Kadri T. 2011. Analisis Penanggulangan Banjir Kota Bekasi Dengan Pengelolaan DAS Bekasi Hulu [Disertasi]. Bogor : Sekolah Pascasarjana, Institut Pertanian Bogor.

Kamase M. 2017. Analisis debit dan tinggi muka air Sungai Tondano di 
jembatan Desa Kuwil Kecamatan Kalawat. Jurnal Sipil Statik. 5 (4): 175-185).

Mulyono D. 2014. Analisis karakteristik curah hujan di wilayah Kabupaten Garut Selatan. Jurnal Konstruksi. 13 (1): 1-9.

Permatasari R, Arwin, Natakusumah D. 2017. Pengaruh perubahan penggunaan lahan terhadap rezim hidrologi DAS (studi kasus: DAS Komering). Jurnal Teknik Sipil. 24 (1): 91-98.

Risyanto. 2007. Aplikasi HEC - HMS untuk Perkiraan Hidrograf Aliran di DAS Ciliwung Bagian Hulu [skripsi]. Bogor : Fakultas Matematika dan Ilmu Pengetahuan Alam Institut Pertanian Bogor.

Sardoii ER, Rostami N, Sigaroudi SK, Taheri S. 2012. Calibration of loss estimation methods in HEC-HMS for simulation of surface runoff (case study: Amirkabir Dam Watershed, Iran). Advances in Enviromental Biology. 6 (1): 343348.

Supit CJ, Mamoto JD. 2016. Prediksi perubahan karakteristik hidrologi akibat perubahan penggunaan lahan sebagai usaha mitigasi banjir di Manado. Jurnal TEKNO. 14 (66): 67-72.

[KemenPU] Kementrian Pekerjaan Umum. 2012. Tata Cara Penyusunan Rencana Induk Sistem Drainase Perkotaan Jilid IA. Jakarta : Kementrian Pekerjaan Umum.

Triatmodjo B. 2016. Hidrologi Terapan. Yogyakarta: Beta Offset Yogyakarta.

Wahid A. 2009. Analisis faktor-faktor yang mempengaruhi debit Sungai Mamasa. Jurnal SMARTek. 7 (3): 204-218.

Wibowo M. 2005. Analisis pengaruh perubahan penggunaan lahan terhadap debit sungai (studi kasus Sub-DAS Cikapundung Gandok, Bandung). Jurnal Teknik Lingkungan. 6 (1); 283-290. 